Universidade Tecnológica Federal do Paraná - UTFPR

Campus Ponta Grossa - Paraná - Brasil

ISSN: 1981-3686/ v. 05, n. 02: p. 606-617, 2011

D.O.I.: $10.3895 / \mathrm{S} 1981-36862011000200012$
Revista Brasileira de Tecnologia

Agroindustrial

\title{
PRESENÇA DE ISOFLAVONAS GLICOSÍDICAS EM RESÍDUO INDUSTRIAL E SUA BIOCONVERSÃO ENZIMÁTICA PARA TRANSFORMAÇÃO EM COMPOSTOS ISOFLAVONAS AGLICONAS
}

\section{PRESENCE OF ISOFLAVONE GLUCOSIDES IN INDUSTRIAL WASTE AND ITS BIOCONVERSION ENZYME FOR TRANSFORMATION INTO COMPOUNDS AGLYCONES}

\author{
Daniel Mantovani ${ }^{1}$; Lúcio Cardozo Filho ${ }^{2}$; Marcos Lúcio Corazza ${ }^{3}$; Gisella Maria Zanin ${ }^{4}$; Nilson Marcos \\ Tazinafo ${ }^{5}$; Silvio Claudio da Costa $^{6}$

\footnotetext{
${ }^{1}$ Universidade Federal do Paraná - UFPR - Curitiba - Brasil danieluns@yahoo.com

${ }^{5}$ Instituto de Tecnologia do Paraná- TECPAR- Brasil
} \\ ${ }^{2,3,4,6}$ Universidade Estadual de Maringá- UEM - Maringá - Brasil cardozo@ deq.uem.br
}

\begin{abstract}
Resumo
Dentre os diversos alimentos funcionais disponíveis atualmente, as isoflavonas se destacam pelos efeitos biológicos e benéficos à saúde humana (atividade estrogênica, anti-estrogênica, antioxidante, antifúngica, entre outros). As isoflavonas são abundantes na soja e seus derivados farináceos e subprodutos, como o melaço de soja. Na natureza, as isoflavonas são encontradas predominantemente na forma de glicosídicos (daidzina, genistina e glicitina), os quais não são assimilados pelo organismo, devido à presença deste açúcar em sua composição. Para que ocorra a assimilação das isoflavonas pelo organismo, é necessário que a mesma se encontre na forma aglicona (sem a presença da molécula de açúcar). O presente estudo propôs como objetivo a bioconversão de compostos glicosídicos em agliconas usando o melaço de soja como fonte de isoflavonas. A enzima $\beta$-glicosidase utilizada na bioconversão foi produzida a partir de diferentes microrganismos filamentosos do gênero Aspergillus (niger ATCC 16404, oryzae ATCC 1003, niger isolado do solo empregando o processo de fermentação no estado sólido (FES) em meio ao substrato farelo de trigo. O maior valor de atividade enzimática determinado, 7,6 U/mg, obtido usando o Aspergillus oryzae ATCC 1003. E para a reação da hidrólise com extrato bruto enzimático contento $\beta$-glicosidase a $40{ }^{\circ} \mathrm{C}$ por 30 minutos convertendo em $100 \%$ os compostos de isoflavonas glicosídicos em compostos de isoflavonas agliconas (daidzeína e genisteína). Todos os compostos obtidos, foram quantificados por cromatografia líquida de alta eficiência (CLAE). A metodologia proposta mostrou-se eficiente para bioconversão de glicosídicos em agliconas a partir do resíduo industrial de melaço de soja.
\end{abstract}

Palavras-chave: melaço de soja, isoflavonas, enzima $\beta$-glicosidase, fungos filamentosos.

\section{INTRODUÇÃO}

A produção nacional de soja no Brasil indica uma safra de 65,16 milhões de toneladas em 2009/10, apresentando um aumento de 598,1 mil toneladas em relação ao último levantamento da safra de 2008/09 (CONAB, 2010). 
Os nutrientes presentes na soja fazem com que ela seja considerada um alimento de alto valor nutricional. As isoflavonas são as formas mais comuns de fitoestrógenos encontrados na natureza apresentando semelhança estrutural com os hormônios estrogênicos, entre eles o $17 \beta$ estradiol (GENOVESE e LAJOLO, 2001).

Indústrias investem em pesquisas e desenvolvimento de novos produtos, transformando o farelo de soja de $48 \%$ em farelo concentrado protéico (SPC) para 60 a 70\% de teor de proteína (IMCOPA, 2009). A partir de uma tonelada de farelo de soja, são produzidos $750 \mathrm{~kg}$ de SPC, os quais geram $250 \mathrm{~kg}$ de um subproduto conhecido como melaço de soja, e diferentemente do SPC, o melaço de soja é um subproduto de baixo valor comercial e gerador de grande impacto ambiental.

O melaço de soja também apresenta isoflavonas glicosídicas em sua composição. No entanto, após transformações bioquímicas via enzimas celulíticas como as $\beta$-glicosidases, ocorre à conversão das isoflavonas glicosídicas em isoflavonas agliconas (daidzeína, genisteína e gliciteína) benéficas à saúde de fácil assimilação pelo organismo (MATSUURA et al., 1993; PARK et al., 2001a).

Fungos das espécies Aspergillus e Trichoderma são bem conhecidos e eficientes produtores de enzimas celulíticas compreendendo as formas endo-1,4- $\beta$-glucanases, celobiohidrolases, exo-1,4- $\beta$-glicosidases e $\beta$-glicosidases (RUEGGER e TAUK-TORNISIELO, 2004).

A enzima $\beta$-glicosidase atua na retirada da molécula de glicose das isoflavonas glicosídicas aumentando o teor de isoflavonas agliconas (SETCHELL et al., 2002; XU et al., 1995). A enzima $\beta$-glicosidase apresenta diversas aplicabilidades em subprodutos agroindustriais provindos do processamento da indústria de soja, atuando principalmente em reações de hidrólise (PARK et al., 2001a).

Estudos já realizados demonstraram altos teores em $\mu \mathrm{g} / \mathrm{g}$ durante a hidrólise de compostos glicosídicos em agliconas quando relacionados à associação da atividade da enzima $\beta$-glicosidase, produzida a partir de microrganismos filamentosos. Essa confirmação já foi realizada por Park et al. (2001b), Aguiar et al. (2003) e IBE et al (2001), os quais avaliaram o uso de microrganismos filamentosos Aspergillus oryzae ATCC 22786. Chun et al. (2008) reportaram o uso dos microrganismos Streptococcus infantarius 12 e Weissella sp. 4 na produção de $\beta$-glicosidase e sua bioconversão em compostos agliconas, reportando que $99 \%$ das formas glicosiladas daidzina e genistina foram convertidas em agliconas daidzeína e genisteína após um período de $6 \mathrm{~h}$ de fermentação. A literatura abrange trabalhos relacionados para obtenção de isoflavonas agliconas provindas da fermentação de diversos produtos fermentados entre eles: tofu, tempeh, shoyu e miso, consumidos principalmente em países asiáticos. As principais fermentações podem ocorrer na forma sólida, sem adição de água ou semi-sólida, com adição de água e adição de nutrientes 
necessários ao crescimento microbiano, podendo ser utilizado em grãos de soja, farelo de soja, proteína texturizada e isolado de soja ente outros produtos derivados de soja.

Estudos realizados por Pereira et al. (2002), Allred et al. (2004) e Allred et al. (2005) são uns dos poucos trabalhos encontrados relacionados à obtenção de isoflavonas a partir de resíduos do processo dos derivados de soja, com boas perspectivas de transformação em outros produtos com alto valor comercial. Diante desta perspectiva, vislumbrou-se o reaproveitamento do melaço de soja para a obtenção de isoflavonas agliconas utilizando um processo de bioconversão enzimática via enzima $\beta$-glicosidase produzida a partir de fungos filamentosos sem nenhuma etapa de purificação.

Tendo em vista o conhecimento de novas técnicas voltadas a bioconversão de compostos provindos de resíduos agroindustriais, este estudo buscou empregar a enzima $\beta$-glicosidase, extrato bruto sem purificação, produzida por fungos filamentosos Aspergillus niger ATCC 16404, Apergillus niger ambiental e Aspergillus oryzae ATCC 1003 via fermentação no estado sólido e realização de um processo de bioconversão enzimática convertendo compostos de isoflavonas glicosícos em agliconas.

\section{Material e Métodos}

A principal matéria-prima, o melaço de soja, resíduo industrial rico em isoflavonas na forma de compostos glicosídicos, foi gentilmente doada pela empresa IMCOPA - Importação, Exportação e Indústria de Óleos Ltda, localizada na cidade de Araucária - Paraná. O farelo de trigo utilizado como substrato durante a FES, foi adquirido da empresa Nutribom Alimentos localizada na cidade de Maringá - Paraná.

Os microrganismos Aspergillus niger ATCC 16404, Aspergillus oryzae ATCC 1003, Aspergillus niger isolado do solo, foram encaminhados para os procedimentos de crescimento, isolamento e identificação das cepas adquiridas e para os fungos ambientais utilizados neste estudo. E posterior armazenamento em temperatura de 6 a $8{ }^{\circ} \mathrm{C}$ para posterior realização da FES, empregado, possibilitando que suas propriedades fisiológicas, enzimológicas e bioquímicas fossem plenamente desenvolvidas (AIDDO et al., 1982).

\section{Produção de $\beta$-glicosidase microbiana via fermentação sólida}

O substrato de farelo de utilizado no ensaio durante a FES foidisposto em frascos erlenmeyers de $250 \mathrm{~mL}$ contendo $20 \mathrm{~g}$ com umidade controlada em $50 \%$ com adição de uma solução com 3\% de uréia como fonte de nitrogênio. E inoculado inoculados com a suspensão de esporos de aproximadamente 1 × $10^{7}$ a 1 × $10^{8}$ esporos/mL do microrganismo e incubados em estufa bacterológica (Tecnal, modelo TE 392/1) controlada a $30^{\circ} \mathrm{C}$ por um período de 96 horas. 


\section{Determinação da atividade de $\beta$-glicosidase}

A atividade de enzima $\beta$-glicosidase foi determinada conforme descrito por Matsuura et al. (1995) com o uso de um espectrofotômetro (Shimadzu UV mini, modelo 1240) e absorbância da solução foi medida a $420 \mathrm{~nm}$. O princípio da ação enzimática procede da seguinte forma: a enzima $\beta$-glicosidase age sobre o substrato sintético (pNPG) liberando $\rho$-nitrofenol como um dos produtos da reação.

\section{Determinação de proteínas totais}

Para a determinação de proteínas totais, foi empregado o método do coomassie brilliant blue BG-250 (BRADFORD, 1976). A absorbância da solução foi medida a $595 \mathrm{~nm}$ em espectrofotômetro (Shimadzu UV mini, modelo 1240).

\section{Extração das isoflavonas}

Para a produção dos extratos metanólicos foi utilizado o melaço de soja. As isoflavonas foram extraídas do melaço de soja conforme método modificado descrito por Grün et al. (2001). A massa foi pesada e eluída na proporção de 1:20 (m/v), com metanol 80\% e agitada constantemente por um período de $1 \mathrm{~h}$ a $25{ }^{\circ} \mathrm{C}$. O sobrenadante foi concentrado em sistema evaporativo a vácuo, rotaevaporador (Fisatom, modelo 801) até atingir o volume de $1 \mathrm{~mL}$. Em seguida completou-se o volume para $5 \mathrm{~mL}$ em balão volumétrico com metanol (grau analítico HPLC). Filtrou-se as amostras utilizando filtros de membranas de 0,22 $\mu \mathrm{m}$ nylon (Alltech, Deerfield, IL) seguido de análise por CLAE.

\section{Determinação dos compostos de isoflavonas por CLAE}

Os extratos concentrados de soja foram determinados por CLAE, de acordo com o método modificado descrito por Park et al. (2001c). Alíquotas de $20 \mu \mathrm{L}$ foram injetadas automaticamente no cromatógrafo líquido equipado com coluna (Microsorb-MV, $5 \mu \mathrm{m}, 100 \AA$ А 4,6申- $250 \mathrm{~mm}$ ) aclopado com detector UV-Vis (modelo Gilson 152). As isoflavonas foram isoladas utilizando sistema de gradiente e eluição, com uma vazão inicial de $0,5 \mathrm{~mL} / \mathrm{min}$, mantendo-se a temperatura da coluna a $35^{\circ} \mathrm{C}$. Foi utilizado um gradiente linear solvente. A (água misturada ao ácido acético na proporção de 19:1 v/v) e metanol como solvente B. Iniciou-se o gradiente com $20 \%$ do solvente B, passando para $40 \%$ em 35 minutos, subindo para $50 \%$ entre 35 e 45 minutos, atingindo $80 \%$ em 75 minutos, decrescendo para $20 \%$ entre 95 e 105 minutos. Um intervalo de tempo de 15 minutos foi deixado para reequilibrar a coluna com $20 \%$ de solvente B entre as corridas realizadas. A detecção foi realizada em absorção de $254 \mathrm{~nm}$. 
Os valores das concentrações de daidzina, genistina, daidzeína e genisteína foram calculados com base nas curvas adquiridas através dos padrões utilizados da empresa Sigma Chemical Co (St. Louis, EUA).

Conversão de isoflavona glicosídica em isoflavona aglicona a partir da enzima $\beta$-glicosidase em extrato bruto microbiano

Foi realizado uma mistura com (extrato concentrado do melaço de soja + enzima $\beta$ glicosidase em extrato bruto + água ultrapura), foi incubada em banho ultratermostático (Quimis, modelo $214 \mathrm{~S}$ ) a $40{ }^{\circ} \mathrm{C}$ durante 30 minutos seguindo metodologia descrita por Lima (2003). Após o processo de hidrólise, a mistura foi filtrada por membranas de 0,22 $\mu \mathrm{m}$ nylon (Alltech, Deerfield, IL) para realização das análises de isoflavonas via CLAE.

\section{Resultados e discussão}

Os microrganismos selecionados Aspergillus oryzae ATCC 22786, Aspergillus niger e Aspergillus awamori (AGUIAR et al., 2003) são os mais pesquisados para a produção de enzima $\beta$ glicosidase utilizando FES. A atividade enzimática de $\beta$-glicosidase produzida pelos microrganismos utilizados (Aspergillus niger ATCC 16404, Aspergillus oryzae ATCC 1003 e Aspergillus niger isolado do solo) foi determinada até o 5 dia de fermentação ou 96 horas baseado em estudo feito por Aguiar et al., (2003).

$\mathrm{O}$ valor do $\mathrm{pH}$ utilizado em todos os testes de atividade enzimática realizados neste trabalho foi de $\mathrm{pH}$ 5,5. Este valor foi o mesmo utilizado por Matssura e Obata (1993) que produziram a enzima $\beta$-glicosidase extraída da soja. O estudo da estabilidade enzimática para $\beta$ glicosidase em extrato bruto foi pesquisado por Lima (2003) que observou que a enzima é termo resistente mantendo sua atividade de até $76 \%$ depois de 4 horas de incubação em uma temperatura de $55{ }^{\circ} \mathrm{C}$, onde obteve $100 \%$ de atividade enzimática na temperatura de 40 a $50{ }^{\circ} \mathrm{C}$ e mesmo após 4 horas de incubação mantinha $90 \%$ de sua atividade. Essas informações foram utilizadas para definir a temperatura de $40{ }^{\circ} \mathrm{C}$ durante 30 minutos para os ensaios realizados na reação enzimática.

Na Tabela 1 encontram-se os valores da atividade enzimática de $\beta$-glicosidase, sem purificação, obtido a partir da FES, utilizando como substrato o farelo de trigo para desenvolvimento dos fungos filamentosos com ATCC e isolados do meio ambiente. Os melhores resultados de atividade enzimática foram obtidos utilizando o Aspergillus oryzae ATCC 1003. Resultados de atividade enzimática semelhantes foram obtidos por Ikeda et al. (1995), Murphy (1982) e Aguiar et al. (2003) utilizando a enzima da soja para a bioconversão de isoflavonas glicosídicas em agliconas. 
Tabela 1 - Valores da atividade enzimática de $\beta$-glicosidase microbiana extrato bruto, substrato farelo de trigo.

\begin{tabular}{|c|c|c|c|c|}
\hline Microrganismos & $\begin{array}{l}\text { Volume } \\
(\mathrm{mL})\end{array}$ & inicialProteínas totais (mg) & $\begin{array}{l}\text { Atividade } \\
\text { (U/mg) }\end{array}$ & Específica \\
\hline Aspergillus oryzae ATCC 1003 & 100 & 0,41 & 7,6 & \\
\hline Aspergillus niger ATCC 16404 & 100 & 0,58 & 6,9 & \\
\hline Aspergillus niger solo & 100 & 0,54 & 5,4 & \\
\hline
\end{tabular}

E os teores de isoflavonas foram quantificados em fração mássica percentual referentes aos compostos glicosídicos e agliconas, presentes no melaço de soja sem adição de enzima $\beta$ glicosidase. As formas glicosídicas são as formas majoritárias quando comparadas aos teores de isoflavonas agliconas, principalmente por não passarem por nenhum processo de fermentação ou hidrólise durante o processo industrial conforme demonstrado na Figura 1. Pereira et al. (2002) estudaram a fração mássica percentual de isoflavonas presentes no melaço de soja encontrando para os compostos glicosídicos, daidzina $38 \%$ e genistina $53 \%$ e para os compostos agliconas, daidzeína 5\% e genisteína 4\%. É importante mencionar que as formas químicas das isoflavonas podem variar dependendo das condições ambientais, solo e variedades do cultivar (HOECK et al., 2000).

Figura 1 - Valores dos compostos daidzina, genistina, daidzeína e genisteína presentes no melaço de soja sem adição de enzima $\beta$-glicosidase.

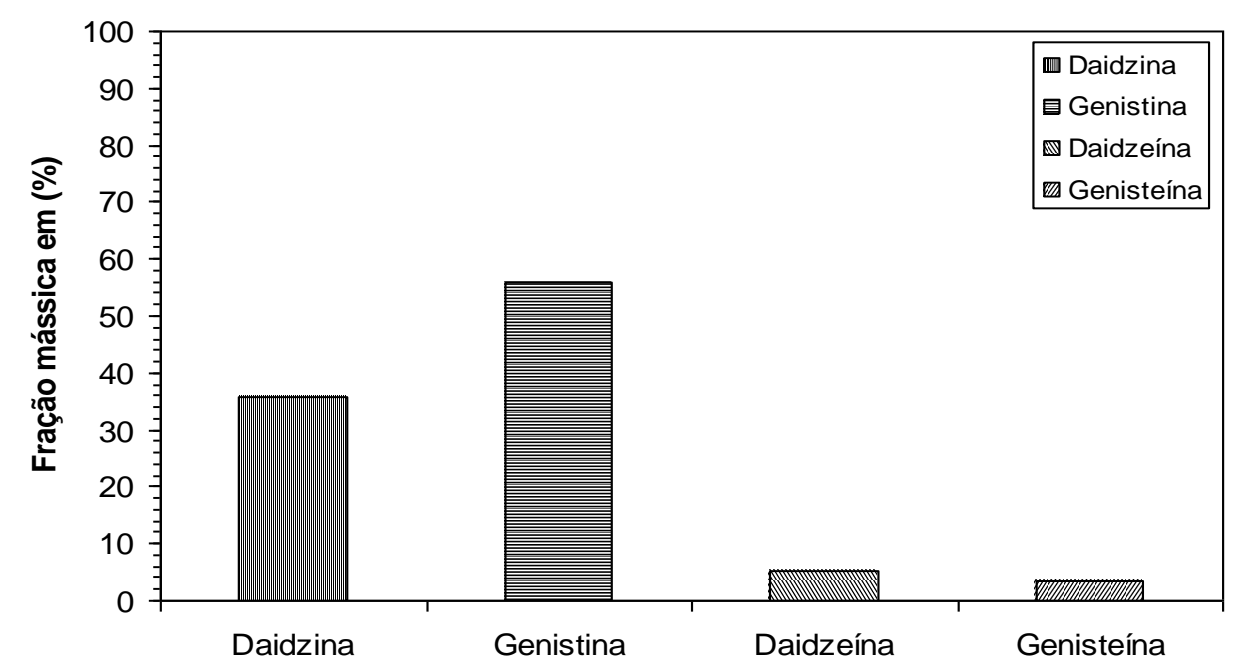

Processo de bioconversão utilizando a enzima $\beta$-glicosidase

As Figuras 2 e 3 demonstram a obtenção das frações mássicas para a bioconversão dos compostos glicosídicos, daidzina e genistina em agliconas, daidzeína e genisteína utilizando a enzima $\beta$-glicosidase extrato bruto, obtidas dos fungos filamentosos (Aspergillus niger ATCC 16404, Aspergillus oryzae ATCC 1003 e Aspergillus niger isolado do solo) após a FES com o uso dos substratos farelo de trigo incubados a $40{ }^{\circ} \mathrm{C}$ durante 30 minutos em meio ao extrato concentrado extraído do melaço de soja. Após o término da reação, os teores de isoflavonas foram quantificados via cromatografia líquida de alta eficiência (CLAE). 
Figura 2 - Valor do composto daidzeína em extrato concentrado após o processo de bioconversão a $40{ }^{\circ} \mathrm{C}$ durante 30 minutos.

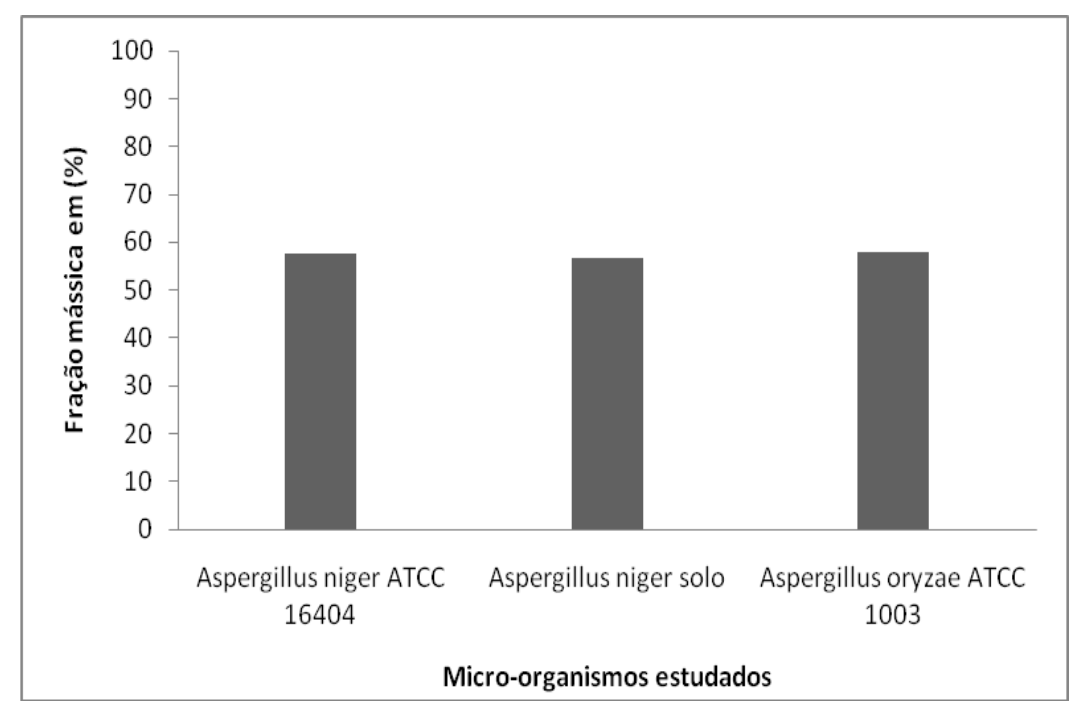

Os teores médios de bioconversão para os compostos daidzeína e genisteína foram de $56,7 \%$ para o composto daidzeína, e $43 \%$ para o composto genisteína.

Figura 3 - Valor do composto genisteína em extrato concentrado após o processo de bioconversão a $40{ }^{\circ} \mathrm{C}$ durante 30 minutos.

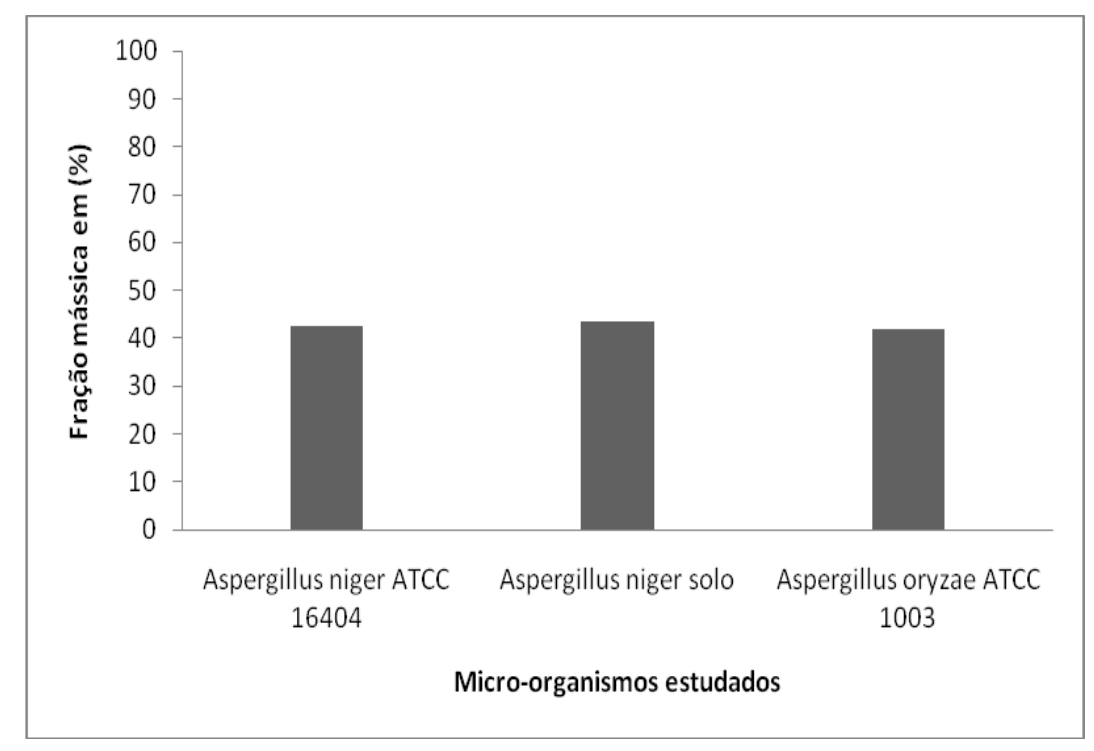

Lima (2003), usando a enzima b-glicosidase produzida pelo Aspergillus niger utilizado na forma de extrato bruto e parcialmente purificado em $40{ }^{\circ} \mathrm{C}$ durante 30 minutos em meio ao extrato metanólico de soja Tozan, observou que as enzimas parcialmente purificadas e na forma de extrato bruto provindas do Aspergillus niger apresentaram praticamente as mesmas taxas de bioconversão, $32 \%$ em relação ao tempo inicial para o composto estudado daidzeína, e ao estudar o teor de genisteína houve um pequeno aumento de $33 \%$ para enzima extrato bruto e $30 \%$ para enzima parcialmente purificada. 
A Figura 4 e 5 representam os perfis cromatográficos obtidos antes do processo de bioconversão da matéria-prima melaço de soja (a) e após seus processos de bioconversão (b a d). A bioconversão ocorreu na forma majoritária levando os extratos concentrados de melaço de soja transformando em compostos agliconas daidzeína e genisteína em 100\% de conversão para os tratamentos com o uso de enzima b-glicosidase (b, c e d).

Figura 4 - Perfil do cromatograma referente à matéria-prima melaço de soja sem processo de bioconversão (a). Processo de bioconversão de isoflavonas glicosídicas em agliconas em função do extrato concentrado de melaço de soja (b). Reação com a enzima $\beta$-glicosidase em extrato bruto, provinda dos substratos farelo de trigo.

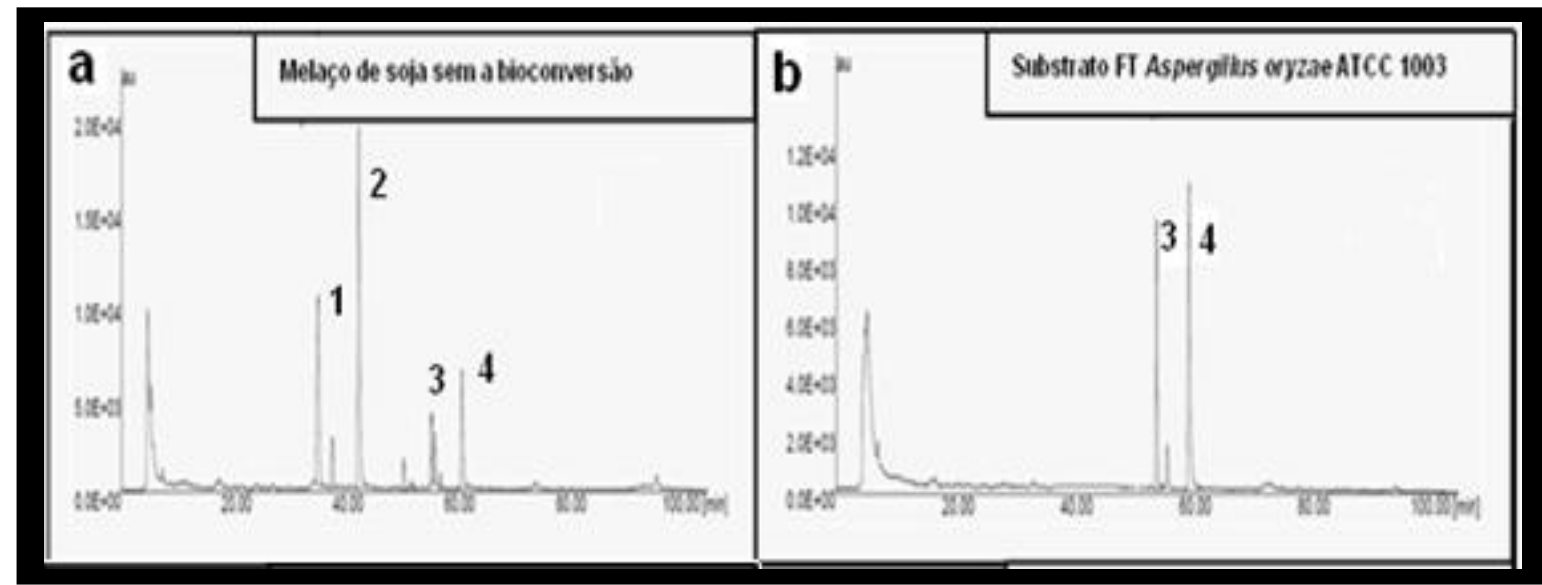

A conversão dos compostos somente foi possível devido à quebra da ligação glicosídica sobre os compostos glicosídicos daidzina e genistina promovida pela ação de enzima b-glicosidase na forma de extrato bruto atuando a uma temperatura de $40{ }^{\circ} \mathrm{C}$ durante 30 minutos. $\mathrm{O}$ efeito do tempo de reação enzimática foi descrito por Lima (2003) ao estudar o uso de (30, 60 e 90 minutos) concluindo que, quanto maior o tempo de reação, maior a diminuição das isoflavonas glicosídicas e conseqüentemente maiores as quantidades dos compostos agliconas. Marazza et al. (2009) estudaram a produção de enzima b-glicosidase produzida via Lactobacilus (L.) rhamnosus CRL981 e sua bioconversão sobre o leite de soja e concluiram que uma temperatura de $37{ }^{\circ} \mathrm{C}$ durante $12 \mathrm{~h}$ de fermentação é capaz de bioconverter $100 \%$ dos compostos glicosídicos transformando em compostos agliconas.

Figura 5 - Perfis dos cromatogramas referentes ao processo de bioconversão de isoflavonas glicosídicas em agliconas em função do extrato concentrado de melaço de soja (c e d). Reação com a enzima $\beta$-glicosidase em extrato bruto, provinda dos substratos farelo de trigo.

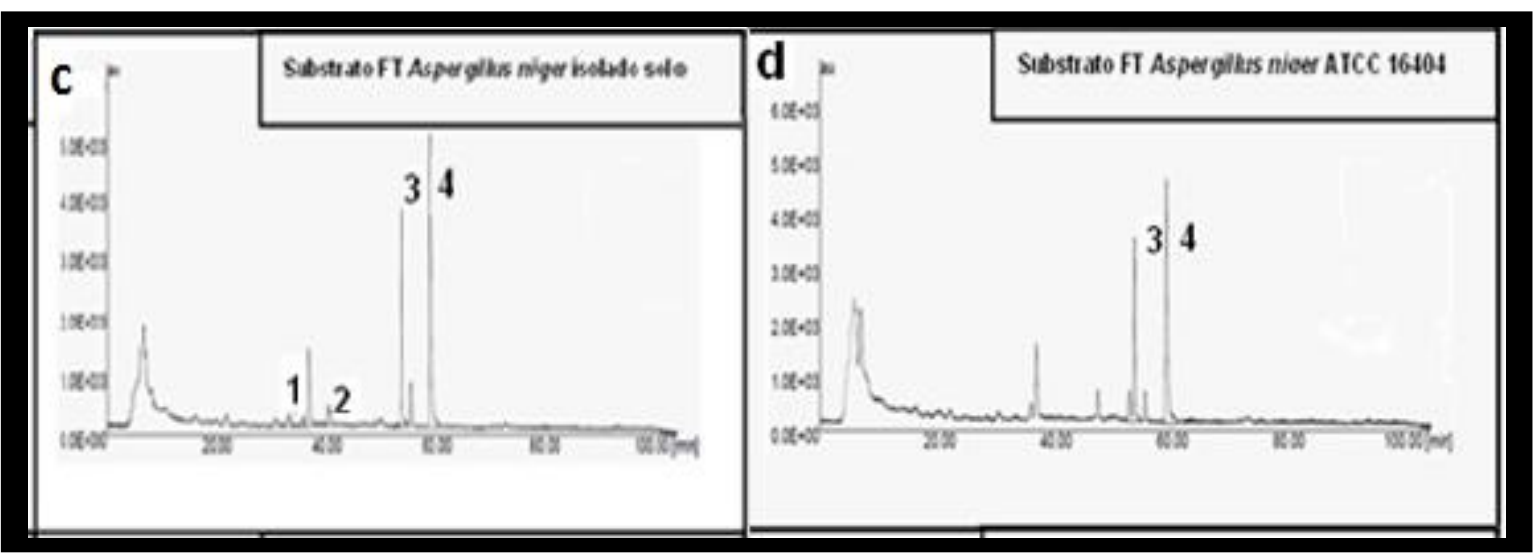


Aguiar e Park (2004) converteram as isoflavonas glicosídicas nas formas daidzeína e genisteína via fermentação semi-sólida com o uso do Aspergillus. oryzae ATCC 22786, utilizando como substrato o farelo de soja em temperatura de $30{ }^{\circ} \mathrm{C}$ durante $48 \mathrm{~h}$ obtendo $100 \%$ da bioconversão.

Para que não houvesse dúvidas sobre os tratamentos utilizados após a extração das isoflavonas presentes no melaço de soja, foram realizados dois tratamentos diferentes. O primeiro tratamento considera o extrato de melaço de soja eluído em meio ao solvente metanol (80\%) após a extração das isoflavonas. O segundo tratamento, após obter o extrato de isoflavonas, foi rotaevaporado até a retirada total da água e solvente metanol presente na amostra.

Os dois tratamentos foram utilizados no procedimento da bioconversão para obtenção de compostos agliconas. O segundo tratamento foi o que demonstrou melhor desempenho por apresentar apenas um dos compostos glicosídicos após o procedimento de bioconversão. Na Figura 6, encontram-se os teores dos compostos glicosídicos e agliconas para os dois tratamentos realizados.

Figura 6 - Valores para os tratamentos com extrato metanólico e extrato concentrado.

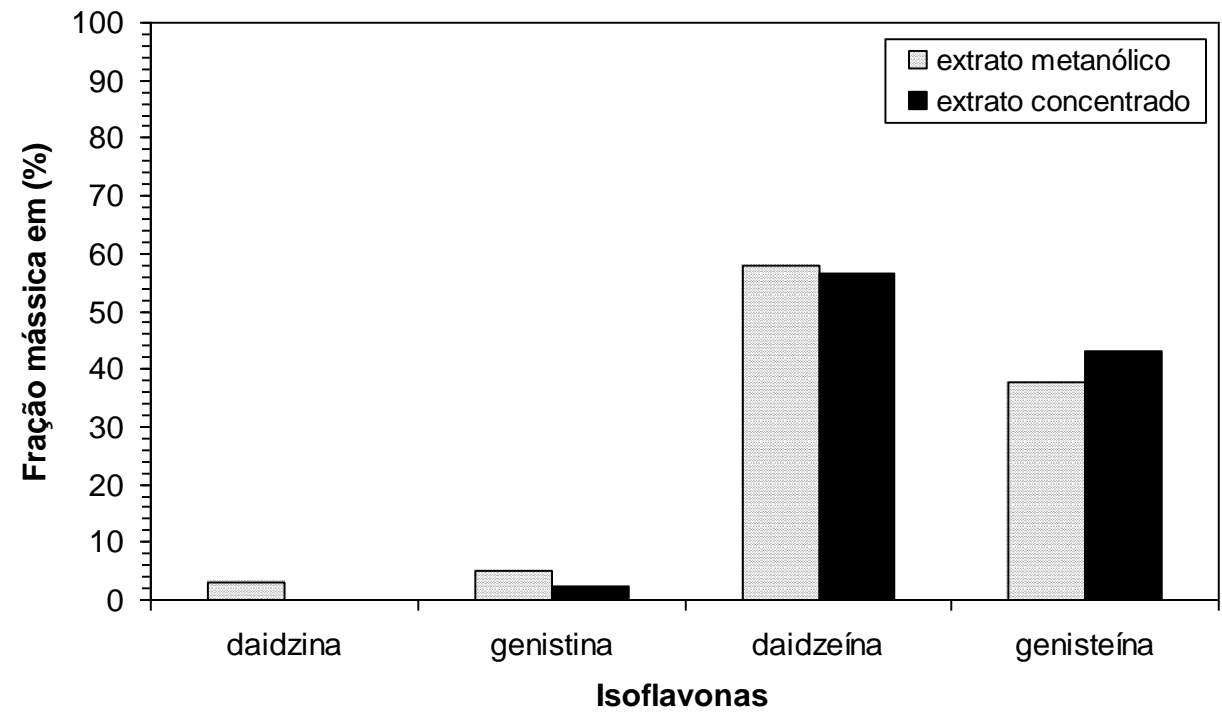

\section{Considerações finais}

Os fungos da espécie Aspergillus niger ATCC 16404, Aspergillus oryzae ATCC 1003, e Aspergillus niger isolado do solo, se desenvolveram em todas as fases de crescimento utilizadas, e principalmente no processo de fermentação na FES. 
O fungo Aspergillus oryzae ATCC 1003 apresentou a maior atividade enzimática de $\beta$ glicosidase quando comparado aos demais fungos estudados para este trabalho em meio ao substrato farelo de trigo.

O extrato bruto enzimático dos Aspergillus apresentou-se estável para as condições utilizadas a $40{ }^{\circ} \mathrm{C}$ durante 30 minutos favoreceu desta forma o processo de bioconversão na transformação dos compostos glicosídicos em agliconas. Como os teores de bioconversão obtidos neste trabalho foram de 100\% para os fungos, Aspergillus oryzae ATCC 1003 e Aspergillus niger isolado do solo utilizando substratos provindo do farelo de trigo, pode-se concluir que a ausência do processo de purificação não foi a etapa determinante.

\begin{abstract}
Among several functional foods available nowadays, isoflavones are important due to beneficial biological effects to human health (estrogenic, antiestrogenic, antioxidant, and antifungal activity among others) Isoflavones are abundant in soy flours, derivatives and by-products such as soy molasses. In nature isoflavones are predominantly found as glycosides (daidzin, genistin and glycitein) which are not assimilated by our organism due to the presence of sugar in their composition. For the assimilation of isoflavones to occur in the body, it is necessary that they are in their aglycone form (without the presence of sugar molecule). The aim of this study was the bioconversion of glycoside compounds into aglycones using soy molasses as an isoflavone source. The $\beta$-glucosidase enzyme used in bioconversion was produced from different filamentous microorganisms of the genre Aspergillus (niger ATCC 16404, oryzae ATCC 1003, niger isolated from soil) using the process of solid state fermentation (SSF) and wheat bran substrate. The highest enzyme specific activity value, $7.6 \mathrm{U} / \mathrm{mg}$, was obtained using Aspergillus oryzae ATCC 1003. And for the hydrolysis reaction with crude extract $\beta$-glucosidase content enzyme at $40{ }^{\circ} \mathrm{C}$ for 30 minutes provided $100 \%$ bioconversion of glycoside isoflavone compounds into aglycone isoflavone compounds (daidzein and genistein). All compounds obtained were quantified by high performance liquid chromatography (HPLC). The proposed methodology was efficient for bioconversion of aglycones into glycosides from industrial waste of soy molasses.
\end{abstract}

Key-words: soy molasses, isoflavone, $\beta$-glucosidase, filamentous fungi.

\title{
Referências
}

AGUIAR, C. L.; SUZUKI, C. N.; PAREDES-GUZMÁN, J. F.; ALENCAR, S. M.; PARK, Y. K. Transformación de las $\beta$-glicosil isoflavonas por fermentación semi- sólida de harina de soja. Ciencia y Tecnología Alimentaria, v. 4, n. 2, p. 115-121, 2003.

AGUIAR, L. C.; PARK, Y. K. Conversão de daidzina e genistina de soja por $\beta$-glicosidase de Aspergillus oryzae. Boletim do CEPPA, Curitiba, v. 22, n. 1, p. 183-195, 2004.

AIDDO, K. E.; HENDRY, R.; WOOD, B. J. B. Solid substrate fermentations. Advances in applied microbiology, v. 28, p. 201-237, 1982. http://dx.doi.org/10.1016/S0065-2164(08)70236-3

ALlRED, C. D.; AllRED, K. F.; JU, Y. H.; GOEPPINGER, T. S.; DOERGE, D. R.; HELFERICH, W. G. Soy processing influences growth of estrogendependent breast cancer tumors. Carcinogenesis, v. 25, n.9, p.1649-1657, 2004. http://dx.doi.org/10.1093/carcin/bgh178

ALlReD, C. D.; TWADDLE, N. C.; ALLRED, K. F.; GOEPPINGER, T.; CHURCHWELL, I. M.; JU, Y. H.; HELFERICH, W. G. DOERGE, D. R. Soy Processing Affects Metabolism and Disposition of Dietary Isoflavones in Ovariectomized Balb/c Mice. Journal of Agricultural and Food Chemistry, v. 53, p. 8542-8550, 2005. http://dx.doi.org/10.1021/jf051246w 
CONAB (Companhia Nacional de Abastecimento). Acompanhamento da safra brasileira de grãos 2009/2010. Disponível em: http://www.conab.gov.br/conabweb/download/safra/4graos_07.01.10.pdf. Jan. 2010. Acesso: 18 Jan de 2010.

CHUN, J.; KIM, J. S.; KIM, J. H. Enrichment of isoflavone aglycones in soymilk by fermentation with single and mixed cultures of Streptococcus infantarius 12 and Weissella sp. 4. Food Chemistry, v. 109, p. 278-284, 2008. http://dx.doi.org/10.1016/j.foodchem.2007.12.024

GENOVESE M. I.; LAJOLO, M. F. Determinação de isoflavonas em derivados de soja. Revista Ciência e tecnologia de alimentos, v. 21, n. 1, p. 3-5, jan/abr, 2001.

GRÜN, I. U.; LI, C. A. K.; LIN, B.; ZHANG, J.; LAKDAS, N. F. Changes in the profile of Genistein, Daidzein, and their Conjugates during Thermal Processing of Tofu. Journal of Agricultural and Food Chemistry, v. 49, p.28392843, 2001. http://dx.doi.org/10.1021/jf010028+

HOECK, J. A.; FEHR, W. R.; MUHRPHY, P. A.; WELKE, G. A. Influence of genotype and environment on isoflavone contents of soybean. Crop Science, v. 40, p. 48-51, 2000. http://dx.doi.org/10.2135/cropsci2000.40148x

IBE, S.; KUMADA, K.; YOSHIBA, M.; ONGA, T. Production of natto which contains a high level of isoflavona aglycones. Journal of the Japanese Society for Food Science and Technology, v. 48, n. 1, p. 27-34, 2001.

IKEDA, R.; OHTA, N.; WATANABE, T. Changes of isoflavones at various stages of fermentation in defatted soybeans. Journal Japanese Society of Food Science and Technology - Nippon Shokuhin, v. 42, n. 5, p. 322-327, 1995. (Citado por ESAKI et al., 1999b).

IMCOPA, Disponível em: www.imcopa.com.br. Ago. 2009. Acesso em: 27 Ago. 2009.

LIMA, F. A. Produção e caracterização de $\beta$-glicosidase vegetal e microbiana e sua aplicação para conversão de isoflavonas glicosiladas em isoflavonas agliconas. Campinas - SP, 2003. Dissertação (Mestre em Ciência de Alimentos) - Faculdade de Engenharia de Alimentos, Universidade Estadual de Campinas.

MATSSURA, M.; OBATA, A. $\beta$-glycosidases from soybean hydrolyze daidzin and genistin. Journal of Food Science, v. 58, n. 1, p. 144-147, 1993. http://dx.doi.org/10.1111/j.1365-2621.1993.tb03231.x

MATSSURA, M.; SASAKI, J.; MURAO, S. Studies on $\beta$-glucosidases from soybeans that hydrolise daidzin and genistin: isolation and characterization of an isozyme. Bioscience, Biotechnology and Biochemistry, v. 59, n. 9, p. 1623-1627, 1995. http://dx.doi.org/10.1271/bbb.59.1623

MARAZZA, J. A.; GARRO, M. S.; GIORI, G. S. Aglycone production by Lactobacillus rhamnosus CRL981 during soymilk fermentation. Food Microbiology, v. 26, p. 333-339, 2009. http://dx.doi.org/10.1016/j.fm.2008.11.004

MURPHY, P. A. Phytoestrogen content of processed soybean products. Food Technology, v. 36, p. 60-64, 1982.

PARK, Y. K.; ALENCAR, S. M.; NERY, I. A.; AGUIAR, C. L.; PACHECO, T. A. R. C. Enrichment of isoflavone aglycones in extracted soybean isoflavones by heat and fungal $\beta$-glucosidase. Food and Science Industry, v. 34, p. 1419, 2001a.

PARK, Y. K.; AGUIAR, C. L.; ALENCAR, S. M.; SCAMPARINI, A. R. P. Biotransformação de isoflavonas de soja. Biotecnologia, Ciência, Desenvolvimento, v. 20, n. 3, p. 12-14, 2001 b.

PARK, Y. K.; AGUIAR, C. L.; ALENCAR, S. M.; MASCARENHAS H. A. A.; SCAMPARINI, A. R. P. Survey of isoflavone contents in Brazilian Soybean. Ciencia y Tecnologia Alimentaria, v. 3, n. 2, p. 156-160, 2001c.

PEREIRA, I. R. O.; DAMASCENO, N. R. T.; PEREIRA, E. C.; TAVARES, L. C.; ABDALLA, D. S. P. Avaliação das concentrações plasmática e urinária de isoflavonas purificadas de soja. Brazilian Journal of Pharmaceutical Sciences, v. 38, n. 3, 2002.

RUEGGER, M. J. S.; TAUK-TORNISIELO, S. M. Atividade da celulase de fungos isolados do solo da Estação Ecológica de Juréia-Itatins, São Paulo, Brasil. Revista brasileira de Botânica, v. 27, n. 2, p. 205-211, 2004.

SETCHELL, K. D. R.; BROWN, N. M.; ZIMMER-NECHEMIAS, L.; BRASHEAR, W. T.; WOLFE, B. E.; KIRSCHNER, A. S.; HEUBI, J. E. Evidence for lack of absorption of soy isoflavone glycosides in humans, supporting 
the crucial role of intestinal metabolism for bioavailability. The American Journal of Clinical Nutrition, v. 76, p. 447-453, 2002.

XU, X.; HARRIS, K. S; WANG, H.; MURPHY, P. A; HENDRICH, S. Bioavailability of soybean isoflavones depends upon gut microflora in women. The Journal of Nutrition, v. 125, p. 2307-2315, 1995.

Submetido em 02 out 2010; Revisão submetida pelos autores em 07 dez 2011, Aceito para publicação em 30 dez 2011. 